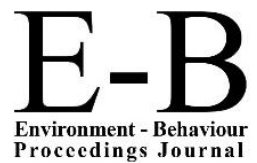
AQoL2017Kuching

http://www.amerabra.org; https://fspu.uitm.edu.my/cebs $3^{\text {rd }}$ ABRA International Conference on Quality of Life "Quality of Life 3"

Riverside Majestic Hotel, Kuching, Malaysia, 14-16 Oct 2017

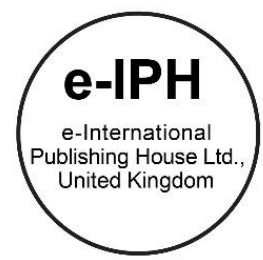

\title{
The Quality of Life of Hospital Inpatients: Exploring visual sphere based on seeing capacity
}

\author{
Maria Myron Charlotta Sengke, Paramita Atmodiwirjo, Yandi Andri Yatmo \\ Department of Architecture, Faculty of Engineering, \\ Universitas Indonesia, Pondok Cina, Beji, Depok City, West Java 16424, Indonesia \\ maria.myron@ui.ac.id \\ $+62-88212094180$
}

\begin{abstract}
This paper study the visual sphere based on a visual surface from a patients' point of view in immobile condition. Capturing image and calculating region were used to identify visual sphere as a collected scene, that established a coordinate system, based on visual degrees in seeing capacity. Coordinate system reveals the most effective of series of the scene in a coordinate mapping of the visual sphere. The most effective of series of the scene will identify the maximum level of seeing capacity. These findings provide new evidence to improving interior design for inpatients in the hospital.
\end{abstract}

Keywords: Visual Sphere; Seeing Capacity, Inpatients, Hospital

eISSN: 2398-4287@ 2017. The Authors. Published for AMER ABRA by e-International Publishing House, Ltd., UK. This is an open access article under the CC BYNCND license (http://creativecommons.org/licenses/by-nc-nd/4.0/). Peer-review under responsibility of AMER (Association of Malaysian Environment-Behaviour Researchers), ABRA (Association of Behavioural Researchers on Asians) and cE-Bs (Centre for Environment-Behaviour Studies), Faculty of Architecture, Planning \& Surveying, Universiti Teknologi MARA, Malaysia.

https://doi.org/10.21834/e-bpj.v2i6.985

\subsection{Introduction}

Vision-related Quality of Life (QoL) in daily living tasks dependent on vision, especially for a patient. In consequence the experience of seeing affected the quality of life of a patient (Finger et al., 2008). In the mechanism of seeing, the human visual system involves the function of the eye and brain in the process of perception (Wahab and Zuhardi, 2013). How a patient in hospital read the environment of seeking information is same as people who read a book to gain information which contained in the text. When seeing mechanism takes place in reading the visual environment, the visual elements become the text that will be read by the patient (Mustikawati et al., 2017). Interior elements as visual elements in particular character overall create the quality of the environmental performance that produces positive impacts on human perception and emotion to improve a wellbeing of the patient (Abdullah et al., 2017). Architects and interior designer have a responsibility in involving the user in the process of designing the spaces. The user perception was prominent to considered by understanding their preferences, through their experience in their daily life, what they perceive, to improve the quality of the environmental performance and to provide a better experience for the users through a clear perspective about their preferences based on their experience. (Ramli et al., 2013).

Recent research mostly mentions visual function as one of the topics that influence the development of vision-related Quality of Life research. In this paper, the visual function defined through the exploration of the visual sphere based on seeing capacity. The visual sphere presented as a visual representation based on flat-sphere perspective. Flat-sphere created by two-dimensional

eISSN: 2398-4287C 2017. The Authors. Published for AMER ABRA by e-International Publishing House, Ltd., UK. This is an open access article under the CC BYNCND license (http://creativecommons.org/licenses/by-nc-nd/4.0/). Peer-review under responsibility of AMER (Association of Malaysian Environment-Behaviour Researchers), ABRA (Association of Behavioural Researchers on Asians) and cE-Bs (Centre for Environment-Behaviour Studies), Faculty of Architecture, Planning \& Surveying, Universiti Teknologi MARA, Malaysia.

https://doi.org/10.21834/e-bpj.v2i6.985 
representations of the three-dimensional visual environment. Visual representation revealed the spatial position that captured from the visual sphere represent the image itself as it is (Casas, 1993). However there still a possibility that visual sphere did not represent the image itself as it is. When design elements in three dimensional seen as a two dimensional it is giving incorrect visual information to interpreting the visual elements. Misinterpretation happens when the observer cannot move from their position and only have one point of view in seeing the visual objects (Gibson, 2015). Gibson explained how visual sphere could be so naive. Although our gaze creates the sphere of vision, we cannot see the totality of our visual environment at once because our sense of sight has a capacity of seeing. Friedman et al. (2018) agreed in seeing capacity it is essential to define the role of foveal and peripheral vision. The eyes will only form sharp images in the region that the eyes fixate on, and that area was in the foveal area.

In this paper we hypothesize in the seeing mechanism, we only see one portion through the foveal vision in our seeing experience of our visual sphere, through peripheral vision at a time. The visual sphere does not present itself, as disconnected of parts of space but as the whole of the visual environment. This paper explores the visual sphere into a mapping of the coordinate system through the visual experience of an immobile inpatient in the hospital based on seeing capacity. The coordinate system consists of the series of a scene that could provide the way of reading visual environment. The visual sphere measured by determinate the seeing capacity of a patient, and the series of a scene included the visual objects. Every scene was measured using "image region analyzer" in Matlab computing software.

\subsection{Literature Review}

The visual sphere that mapping into the coordinate system could provide a base of a series of a scene, to define a boundary as the set of points of view. Casas (1993) describe through this concept, provide us with a geometrical analysis of the human visual sphere and a way to represent that visual sphere on a surface. Visual sphere mapped into a coordinate system based on seeing capacity.

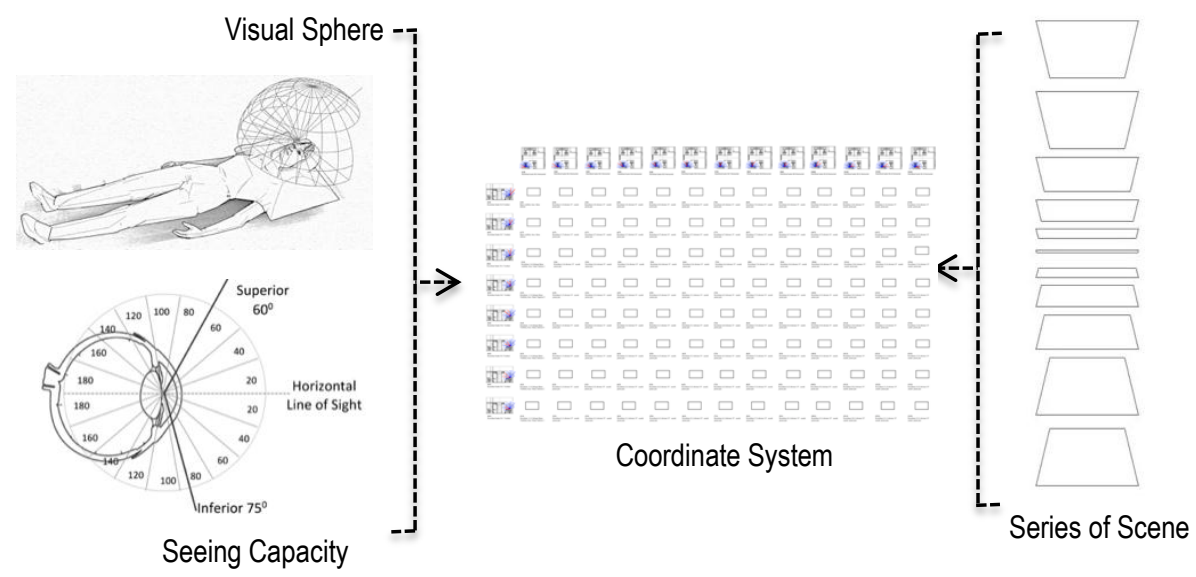

Fig. 1. Visual Sphere Mapping into Coordinate System

(Source: Sengke and Atmodiwirjo, 2017)

Sengke and Atmodiwirjo (2017) and Johanes et al. (2015) identified there is one advantage point of the observer's field of view that could be a base for seeing the environment (Sengke and Atmodiwirjo, 2017; Johanes et al., 2015). From that point, a person can turn his gaze in any direction around him up, down, left, right, front, back-and in exploring the visual sphere. Dohse (2007) found the field of view has a specific degree which is 1350 , that divided into two part, superior and inferior vision. The superior vision area, start from the upper side of the horizontal line of sight, and the inferior vision is the lower side. The focus area in vision divided into three part: the first part is the focus of the visual range 50-100 as a precision view in seeing text, 100-300 to see the shape of the object, and 300-600 to see the colour (Chua et al., 2016). Through this division, the measurements use the visual range 300 as the focus of the visual range of the objects.

The coordinate system based on seeing capacity in visual sphere provides a basic mapping as a whole viewing way of the detail view. Pallasmaa and Robinson (2015) explained that naturally, the direction of seeing has the important stages, the first stage is looking at the whole first and second stage is add detail to it. Detail by detail complete the whole of the visual sphere, the perceiving of the entire entities of the environment begins with the precise to every detail of the whole in capturing the complexities of environmental objects. The exploration of the experience of seeing, of identification of the environment can stimulate a person's perception process and produce a positive distraction that can support recovery for the patient.

\subsection{Method}

The setting of this paper is the point of view of the inpatients' in immobile condition, experiencing the reading of visual environment in patients' room in the hospital. The object research is the series of scenes of the coordinate system, including the elements of the interior in the inpatients' room as the objects visual such as a ceiling, wall, and floor, which is consist of medical devices, hospital curtains, lamps, inpatients' bed and other hospital equipment. 


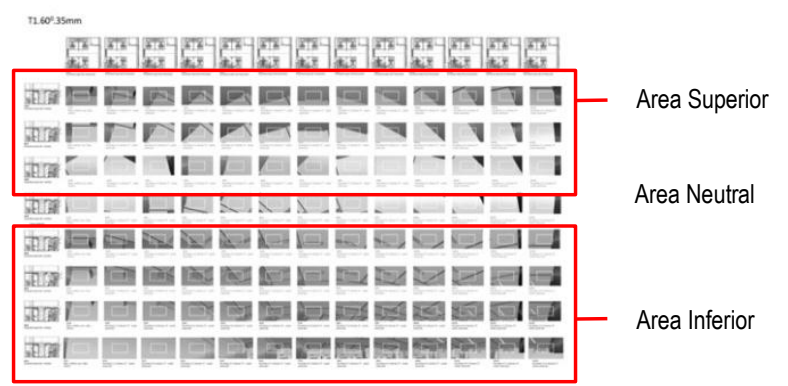

(a)

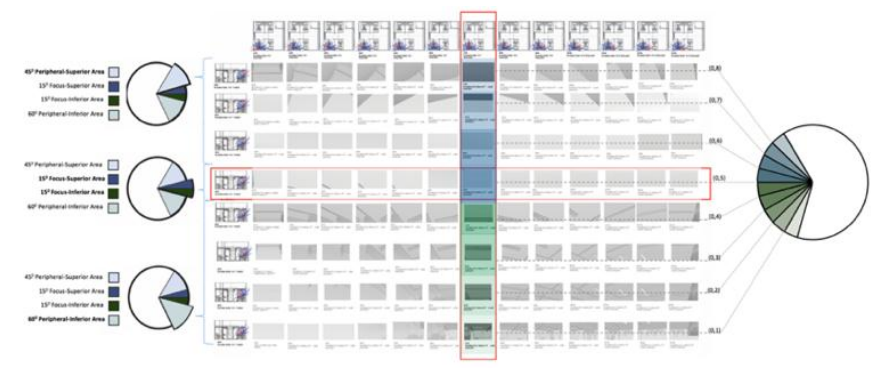

(b)

Fig. 2. (a) Coordinate System; (b) Focus Vertical Range (Source: Sengke and Atmodiwirjo, 2017)

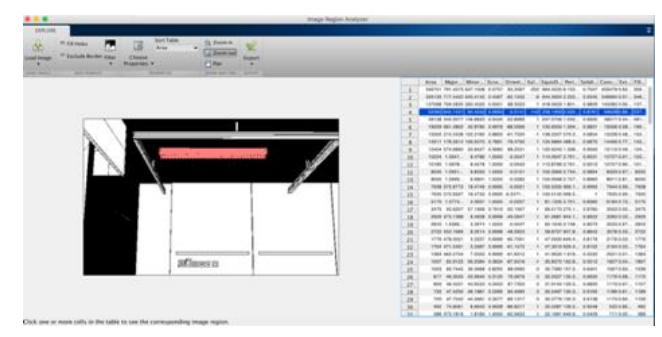

(a)

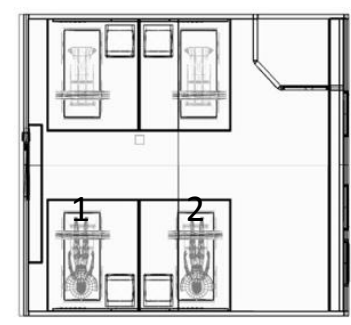

(b)

Fig. 3. (a) Matlab Computing Software Illustration, (b) Floor Plan of The First and The Second Position of Inpatients (Source: Sengke and Atmodiwirjo, 2017)

This study uses a capturing image to record the traces of the experience of seeing based on seeing capacity. Every movement of the inpatients' eye projected into a scene. Every action of capturing image determined by the angle of view by a camera. The eye movement of the inpatients' represented by the range of vertical focus degree $30^{\circ}$ which shifts as far as $15^{\circ}$. The shift per $15^{\circ}$ was in the range of $60^{\circ}$ to the edge of the superior vision area and $75^{\circ}$ as the edge of inferior vision area. Each capture per $30^{\circ}$ generates a scene. Each scene that has been collected into a series of scenes is subsequently mapped by dividing superior-inferior vision of focus and peripherals area. Each series of scene of vertical and horizontal scenes further established a coordinate system that representing flat-sphere perspective (Fig.2a)

After the coordinate system was established, we calculate the region in each of scene using "image region analyzer" in Matlab computing software to identify the characteristic of the object visual. Every scene was read as binary images that show the boundary as a region of every visual element. The calculating start through the properties of the region and gave a result such as an area, convex-area, eccentricity, equivalent-diameter, Euler-number, extent, filled-area, perimeter, major-axis-length, minor-axis-length, orientation, perimeter, and solidity (Figure.3a). In this case, the result focused on the area calculation. The mapping of the visual sphere into a coordinate system applied in two positions. The first position is at the corner of the inpatients' room and the second position is in the middle of the room, it is shown in (Fig.3b).

\subsection{Result}

Visual sphere based on seeing capacity develop a coordinate system. Through the coordinate system, it shows that the coordinate $(7,1)$ until $(7,8)$ is the potential maximum level of the seeing capacity. This coordinate has a series of the scene of the vertical range that divides into two parts which are the superior and inferior vision area. The inferior vision area is $(7,1)$ until $(7,5)$, and the superior vision area is the coordinate of $(7,5)$ until $(7,8)$. Through this superior and inferior vision coordinate, determined the potential level of the visual environment in inpatients' room in the first and second position. 
Table 1. Series Scene of First and Second Position of Patient's The experience of seeing

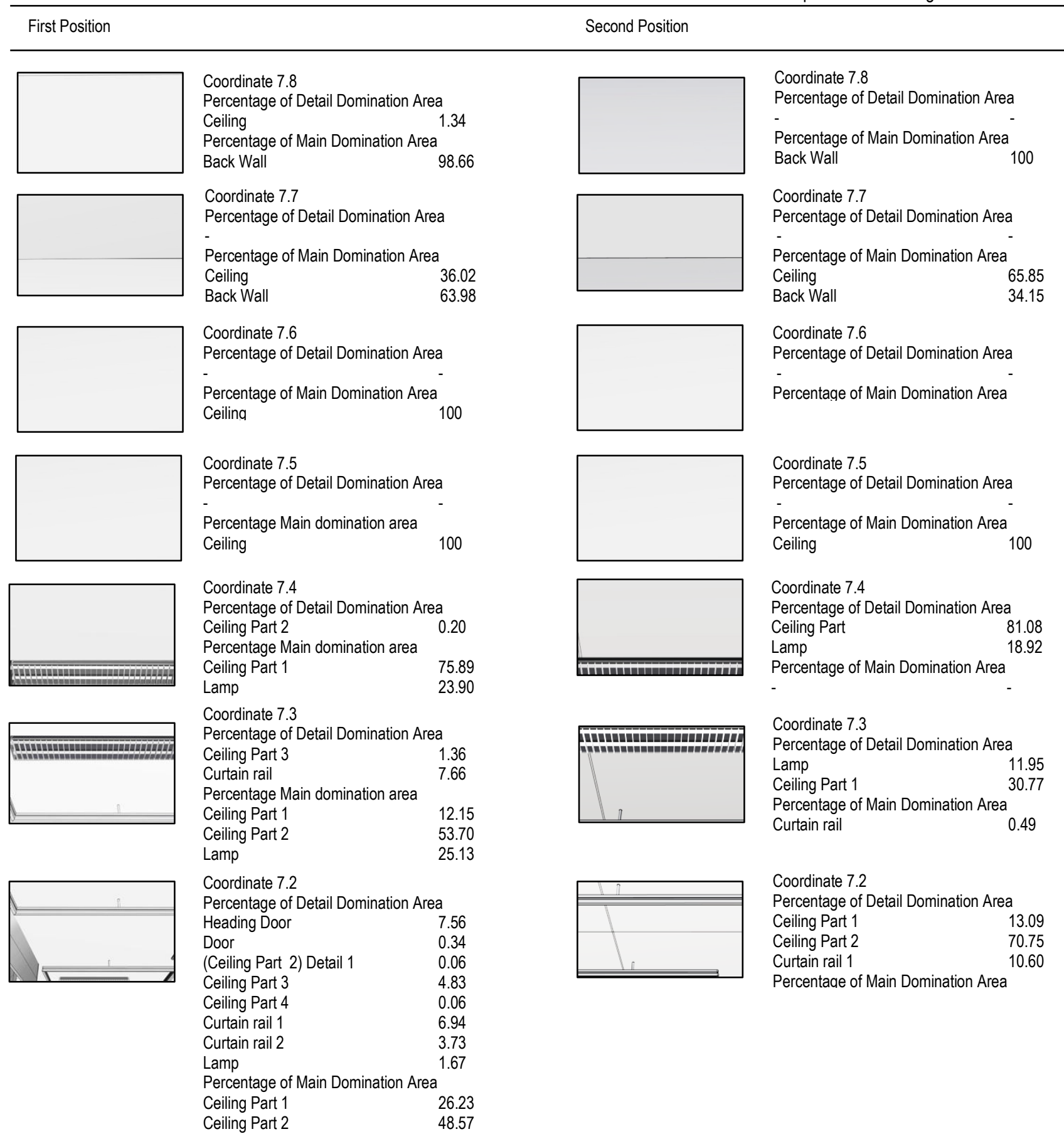

Every scene on the first and second position has a calculated result that revealed two categories; the first category is the main domination area. The main domination area was representing the area element without any detail of element. The domination elements in the main domination area was a blank ceiling or a blank wall. The second category is the detail domination area. The detail domination area was representing the detail element area that was dominating the inpatients' visual sphere. The dominating detail elements in the inpatients' visual sphere in the detail domination area which is: curtain rail, heading door, utilities, detail of back wall, doors, windows, ventilation, switch on and lamp. 


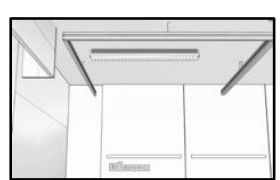

Coordinate 7.1

Percentage of Detail Domination Area

Heading Door $\quad 5.13$

Door $\quad 0.62$

Front Wall Part 1 (FWP1) $\quad 7.67$

FWP2 Detail 1

FWP2 Switch on 1 (FWP2S01) $\quad 0.06$

(FWP2S01) Detail $1 \quad 0.01$

(FWP2So1) Detail $2 \quad 0.01$

FWP2 Switch on 2 (FWP2So2) $\quad 0.06$

(FWP2So2) Detail $1 \quad 0.02$

FWP2 Switch on 3 (FWP2So3) $\quad 0.04$

(FWP2So3) Detail $1 \quad 0.01$

(FWP2So3) Detail 2l $\quad 0.01$

FWP2 Switch on 4 (FWP2S04) $\quad 0.05$

(FWP2S04) Detail $1 \quad 0.01$

FWP2 Switch on 5 (FWP2S05) $\quad 0.05$

(FWP2S05) Detail $1 \quad 0.01$

FWP2 Switch on 6 (FWP2S06) $\quad 0.05$

(FWP2S06) Detail $1 \quad 0.02$

FWP3 Detail $1 \quad 0.48$

Front Wall Part $4 \quad 1.08$

Ceiling Part $1 \quad 8.69$

Ceiling Part $3 \quad 1.68$

Curtain rail $\quad 4.98$

Lamp 2.88

Percentage of Main Domination Area Left

Wall 14.33

Front Wall Part 2 (FWP2) $\quad 18.41$

Front Wall Part $3 \quad 18.76$

Ceiling Part $2 \quad 14.42$

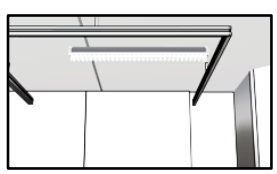

Coordinate 7.1

Percentage of Detail Domination Area

Ceiling Part 1

Ceiling Part $2 \quad 0.02$

Curtain rail 1

Curtain rail 2

Lamp 5.32

Front Wall Part 3

Front Wall Part 4

Front Wall Part 5

Front Wall Part 6

Percentage of Main Domination Area

Ceiling Part 3

Ceiling Part $4 \quad 11.26$

Front Wall Part 1

Front Wall Part 2

(Source: Sengke and Atmodiwirjo, 2017)

The total of the main area and the total of detail area represents the number of visual elements in the patients' visual sphere. The percentage of detail dominating area and the percentage of main dominating area represent the percentage of the area in inpatients' visual sphere area. The higher the percentage of area domination the lower the total element. The more extensive the area, the more there is no variant in visual elements.

\subsection{Each of Scene of First and Second Position}

The criteria of every scene of the first and second position are defined by four categories which are; 1)percentage of detail domination, 2)percentage of main domination area, 3)total main element and 4)total detail element, shown in (Table.1). The result indicates that in the superior vision coordinates, a variant of the visual elements was found less. This effect denotes that visual elements in superior vision coordinates have a low contribute to the patient's experience of seeing. The lack of contribution of visual elements in the patient's experience of seeing indicated by the low rate of percentages in the detail domination area and the total detail element, of the superior vision area, and vice versa.

Total main elements from every scene revealed the elements with the high rate of percentages was back wall and ceiling. Total detail element shows that in patients' superior vision area only saw the ceiling and the back wall. In point of fact, the object visual with the high rate of percentages in detail domination area and the total detail element include curtain rail, lamp, and switch on.

\subsection{Series of Scenes of First and Second Position}

The results of the percentage of the superior and inferior vision areas did not show significant differences in the first and second position. The result describes the differences of the experience of seeing was appear only on the based on the vertical visual range. At the first point, the vertical visual range in the coordinate $(7,1)$ found a high rate of the total main element and total detail element. Both of this categories represent the variant of the visual elements. In coordinate $(7,1)$ it was the highest scene that has the most visual elements in the vertical visual range. The result revealed how the interior elements take part in the inferior vision area rather than in superior area.

The coordinate (7.2) until (7.8) have no significant differences between the first and second condition in categories of total main elements and total detail elements. In the second position, the coordinate (7.1) until (7.5) in the percentage of detail domination area has a lower rate than the first position. It is due to the second position that has the lower rate in total detail element. It described that the more detail visual elements, the more variant in visual elements in the experience of seeing. The percentage of detail domination area was inversely proportional to the percentage of main domination area.

The second position in the percentage of detail domination area is showing lower rate than the first position. In the percentage of main domination, the second position indicating a higher rate than the first position. It is defined the lower percentage detail domination area, the higher percentage main domination area. The series scene of the coordinate (7.1) until (7.8) indicate the higher 
potential level of vertical visual range the lower total detail elements and the percentage of detail domination area. On the contrary the lower potential level of vertical range the higher total main element and the percentage of main domination area. It revealed that in the best area of the patients' capacity of seeing have less contribution to the patients' spatial experience in inpatient room.

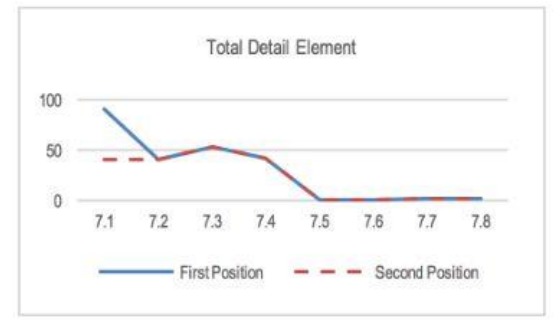

(a)

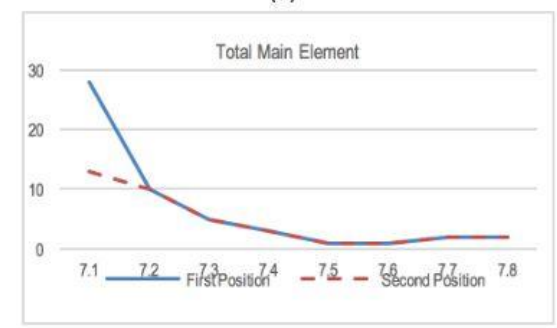

(c)

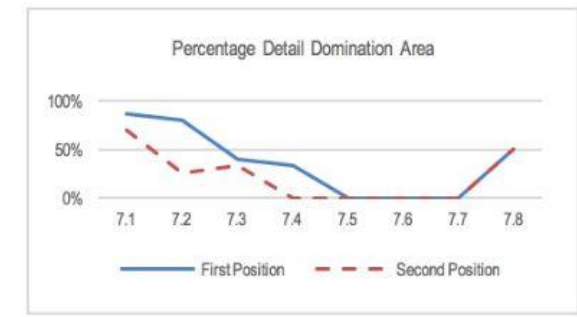

(b)

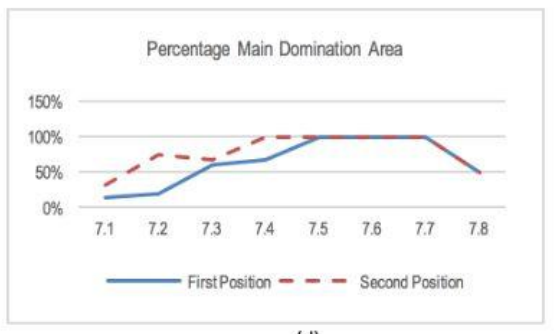

(d)

Fig. 4. (a) Total Main Element; (b) Focus Vertical Range, (c) Total Detail Element, (d) Percentage Main domination area (Source: Sengke and Atmodiwirjo, 2017)

\subsection{Conclusion and Recommendation}

The result of the percentage of detail domination and main domination affirmative our hypothesis, inpatients only see a part of the whole of the visual sphere in the experience of seeing. The visual environment does not present itself as disconnected of parts of space but as a unity of the parts. Inpatients have a part that they cannot be seen. The parts that cannot be seen in the inpatients' capacity of seeing was a disconnected part in the inpatients' visual sphere. Likewise, with the parts of the elements in each of scene, the elements as a whole were only be seen as a part in inpatients' capacity of seeing. The other parts of the element that can not be seen as a disconnected part, in the inpatients' visual sphere that restricted, by the boundary of the vision area. Seeing a part of the whole of the visual sphere gives a possibility in perceiving misinterpretation. The result of total detail element and the total main element explains that in the positive z-axis as a potential of view area, the ceiling was the highest percentage of the detail dominating. The highest percentage of the detail dominating demonstrates that in the most inpatients' visible area have a less significant visual element in exploring space. It is clear that architects and interior designer in designing the inpatient's room were no regards to the point of view of the inpatients in bedridden condition. The demeanour of lack of consideration of the patient's visual experience leads to the indifference of patient's visual experience.

This research stands for evidence-based design in evaluating inpatients' room. Through this evaluation, it recommends process design to be more considerate in involving the experience of seeing of patient in a design process. The consideration in process design that involves the seeing experience of patient give a contribution in strengthening the relationship between patient and the patient environment. The strong relation between patient and inpatient room in the hospital as their environment improve the quality of life of the patient and enhance the well-being of the patients. Furthermore, this study could be continued to strengthen research involving changes in patient recovery associated with the experience of seeing and a particular of visual elements in the inpatient room.

\section{Acknowledgements}

This research was supported by a grant from Hibah Publikasi International Terindeks Untuk Tugas Akhir Mahasiswa UI (PITTA) Tahun 2017 Awarded to Prof. Yandi Andri Yatmo, S.T., Dip. Arch., M.Arch., PhD and Prof. Paramita Artmodiwirjo, S.T., M.Arch., PhD. The statements made, the data presented, and the views expressed are fully the responsibility of the author.

\section{References}

Abdullah, M., Ali, W. N. A. W., Ghani, I., (2017). Exploring the Elements of Natural Landscape Character in Engaging Children with their Natural Environment. E-BPJ, 2(5), 209-214.

Casas, F. R., (1993). The Limit of the Visual environment. Leonardo, Vol. 26, No. 2, 159-164. 
Chua, S. H., Perrault, S.T., Matthies, D. J. C., Zhao. S., (2016). Positioning Glass: Investigating Display Positions of Monocular Optical See-Through Head-Mounted Display. Chinese $\mathrm{CHI}$, San Jose.

Dohse, K. C. K. C., (2007). Effects of Field of View and Stereo Graphics on Memory in Immersive Command and Control. Thesis, Master Science, lowa State University.

Friedman, N. J., Kaiser, P. K., Trattler, W. B., (2018). Review of Ophthalmology: Third Edition. Elsevier. China.

Johanes. \& Atmodiwirjo. P. (2015). Visibility Analysis of Hospital Inpatient Ward. International Journal of Technology, Vol. 3, p.400-409.

Mustikawati, T., Yatmo, Y. A., Atmodiwirjo, P., (2017). Reading the Visual Environment: Wayfinding in Healthcare Facilities. E-BPJ, 2(5), 169-175.

Ramli, N. H., Ahmad, S., \& Masri, M. H., (2013). Improving the Classroom Physical Environment: Classroom users' perception. Procedia-Social and Behavioral Sciences, Vol. 101, 221-229.

Sengke, M. M. C., \& Atmodiwirjo, P., (2017). Using Isovist Application to Explore Visibility Area of Hospital Inpatient Ward. IOP Conference Series: Materials Science and Engineering, 185. 012008. 10.1088/1757-899X/185/1/012008.

Wahab, M. H. A., \& Zuhardi, A. F. A., (2013). Human Visual Quality: Art gallery exhibition. Procedia-Social and Behavioral Sciences, Vol. $101,476-487$.

Yousefi. Z., Hosseini, S. B., Yazdanfar, S. A., Maleki. S. N., (2017). Promoting the Residents' Sense of Belonging in Housing Design. Asian Journal of Behavioural Studies, AjBeS, 2(5), 33-43. 